\title{
Assessing resultativeness of enterprise adaptation to market changes in the digital economy
}

\author{
Rinat Khusnutdinov ${ }^{1, *}$, Julia Stepanova ${ }^{2}$, and Natalia Meshkova ${ }^{2}$ \\ ${ }^{1}$ Moscow State University of Civil Engineering, 26, Yaroslavskoye Shosse, Moscow, 129337, Russia \\ ${ }^{2}$ Lugansk Vladimir Dahl State University, 20a, Molodyozhny Kvartal, Lugansk, Ukraine
}

\begin{abstract}
Our research aims to develop and scientifically justify theoretical provisions and practical recommendations used for assessing resultativeness of a business enterprise adaptation to changing markets in digital economic environment which, in addition, creates opportunities for industrial enterprises to improve their resultativeness. In our study, assessment of enterprise adaptation performance is based on the method of indicator system development and logical analysis methods. Methodology described in this paper uses formula for calculating and algorithm for measuring industrial enterprise adaptation performance and, therefore, provides an opportunity to obtain useful information on effectiveness of company adaptation to market changes in the digital economy.
\end{abstract}

\section{Introduction}

The advent of the Internet and digital technologies have challenged businesses of all forms of ownership and their activities. The growing role of information and knowledge in business, the need to reduce production costs, and the rapid development of digital information technologies have created an almost new type of economy-the digital economy. The subject of the digital economy in its most General form is the economic relations that develop in the process of production, exchange, distribution and consumption of scientific and technical information through digital information technologies, as well as the economic laws that govern the development of these processes. Though digital environment offers modern businesses a plethora of opportunities to improve their performance, only few enterprises can quickly adjust to the changes in their external environment caused by the economy digitalization/ Moreover, situations when positive changes designed to improve operating activities of business have had an opposite effect, just prove the fact that not every company is able to adapt effectively to the digital era innovations. Monitoring of companies' efforts to adapt and adjust to the digital environment requires understanding and appropriate assessment of the process effectiveness which, thus, may result in timely corrective actions and in overall business success.[1]

Though Russia's manufacturing companies seem to be less affected by digitalization than its banking and service sectors, their further development in the face of fierce competition for consumers and limited resources is impossible without effective usage of digital technologies. [1]
The digital development driver for the industrial sector, the Industry 4.0 concept, with a "smart factory" being its technological core, was proposed at the Industrial Exhibition in Hanover, Germany, in 2011. [26]

Industry 4.0 stimulates companies to adjust their product and service portfolios to individual needs and changing wants of their customers, thus, providing companies' sustainability in their markets.

\section{Materials and Methods}

Our review of recent research studies and publications has revealed a keen interest of foreign and Russian scientists and economists such as R. Ackoff [7], P. Drucker [8], R. Nelson [9], G. Dvas [10], J. Schumpeter [11], V. Ananyin [12], S. Bodrunov [12], L. Garifova [14], G. Rudenko et al.[15] in the issues of business adaptation to digital economic environment.

According to the authors, to assure their sustainability business enterprises should adjust their internal characteristics to external environment, consider external trends, and choose the best possible adaptation strategy from a variety of strategic alternatives available.

Unfortunately, such a wide variety of change adaptation options makes it much more difficult for a company management to initiate the adaptation process and monitor it. [16-20]

It is obvious, that in the era of global instability survival of business entities crucially depends on availability of adaptation mechanisms, allowing them to stabilize and balance their activities, transform their markets, and meet their industry growth challenges. While adjusting business systems to changeable external factors, these mechanisms, however, save the

* Corresponding author: husnutdinovra@mgsu.ru 
fundamental characteristics of these systems and their identity.

In this context, assessment of a company adaptation resultativeness together with its quantification becomes an essential indicator of business failure or success in unstable external environment.

In general terms, our methodology for assessing the effectiveness of business adaptation to the digital environment can be presented as follows:

1)the purpose of the methodology: obtaining analytical data on effectiveness of company adaptation to market changes conditioned by the digital economy in order to monitor economic security of a business;

2)the application of the methodology: assessing effectiveness of companies' activities in adaptation to market changes conditioned by the digital economy, considering their suppliers, consumers and competitors;

3)the frequency of the methodology use: once a year, a quarter, a month, or at the request of company management;

4)instructions on the step-by-step assessment procedure: presented in the report on the research results;

5)documents required to support assessment procedures: input forms for evaluation and optimization of adaptation performance indicators.

Quantity estimation of a company effectiveness in its adaptation to changes in external environment conditioned by digitalization is based on the author's formulae for calculating planned result of adaptation and adaptation effectiveness. These calculations use the enterprise's actual and potentially possible performance indicators, which describe its state at the beginning and at the end of the reporting/ study period.

Classification of performance indicators characterizing results and effectiveness of enterprise adaptation to the digital economy environment:

1. Potentially possible values of indicators at the beginning of the reporting period $\left(\mathrm{PPV}_{0}\right)$ : the qualitative values of company performance indicators, which correspond to the minimum level of discrepancy between the company performance and the environmental conditions at the beginning of the reporting/ study period. They are used to calculate planned company adaptation performance. Their numerical values depend on the market players/ participants, the company's strategic goals and its experience, and the reference values of its performance indicators. The achievement of these indicator values guarantees the company the best possible performance in the current conditions.

2. Potentially possible values of indicators at the end of the reporting/ study period $\left(\mathrm{PPV}_{1}\right)$ : the qualitative values of company performance indicators, which correspond to the minimum level of discrepancy between the company performance and the environmental conditions at the end of the reporting/ study period. They are used to calculate actual company adaptation performance. Their numerical values depend on the market players/ participants, the company's strategic goals and its experience, and the (industrial) reference values of indicators. The achievement of these indicator values guarantees the company the best possible performance in the current conditions.

3. Actual indicator values at the beginning of the reporting period $\left(\mathrm{AV}_{0}\right)$ : the actual values of company performance at the beginning of the reporting/ study period, the starting point in the process of company adaptation. Actual indicator values are set and calculated at the beginning of the reporting/ study period.

4. Actual indicator values at the beginning of the reporting period $\left(\mathrm{AV}_{1}\right)$ : actual values of company performance at the end of the reporting/ study period. Actual indicator values are set and calculated at the end of the reporting/ study period: $\mathrm{AV} 1 \leq \mathrm{PPV} 1$. If $\mathrm{AV}_{1}=$ $\mathrm{PPV}_{1}$, the planned result of adaptation is achieved.

Driven by market changes in the digital economic environment, potentially possible indicator values (PPV) or economic security indicators demonstrate such an efficiency of a company operation, that corresponds to the state of its economic security, and is characterized by the minimum level of discrepancy between the company performance and its external environment conditions. Potentially possible values of company performance indicator can be determined for the beginning $\left(\mathrm{PPV}_{0}\right)$ and end $\left(\mathrm{PPV}_{1}\right)$ of the reporting/ study period. The difference in value between $\mathrm{PPV}_{0}$ and $P P V_{1}$ may result from a time-lag changes in players' power in digitally-driven markets, which, thus, lead to changes in potential values of indicators.

By efficiency of adaptation to the digitally-driven economic environment we mean the degree to which planned results or targets of a company adaptation activities have been met, which is calculated as the ratio of actual results of adaptation to the planned ones. [2122]. In our research, we are of the view that the result of adaptation means the difference between the levels of discrepancy between the company performance and the environmental conditions measured after and before the implementation of the company's adaptive actions, being expressed in terms of indicator values. Thus, this planned or targeted result as the ultimate goal of the company's adaptive actions is viewed as achieving the minimum level of this discrepancy described in terms of potentially possible values of the company performance indicators.

In our case, the formula for calculating the result of adaptation (RA) takes the following form:

$$
R A=D_{1}-D_{0}
$$

where $D_{1}$ is the discrepancy between the company performance and the environmental conditions measured at the end of the reporting/ study period after the implementation of adaptive actions:

$$
D_{l}=P P V_{l}-A V_{l}
$$

$\mathrm{D}_{0}$ is the discrepancy between the company performance and the environmental conditions measured at the beginning of the reporting/ study period before the implementation of its adaptive actions:

$$
D_{0}=P P V_{1}-A V_{l}
$$


In this case, the result of adaptation will be presented in the following form:

$$
R A=\left|P P V_{l}-A V_{l}\right|-\left|P P V_{0}-A V_{0}\right|
$$

Achieving the minimum level of the discrepancy between the company performance and its environmental conditions is characterized by the following equation:

$$
P P V=A V \text {, i.e. } P P V_{1}-A V_{1}=0
$$

The planned or targeted result of adaptation, which is set before the start of adaptation process, can be presented as follows:

$$
A R_{p l}=-\left|P P V_{0}-A V_{0}\right|
$$

The formula for calculating a company resultativeness of adaptation (EA) to the external environment, shaped by the digital economy, will take the following form:

$$
E A=\frac{\left|\mathrm{PPV}_{1}-\mathrm{AV}_{1}\right|-\left|\mathrm{PPV}_{0}-\mathrm{AV}_{0}\right|}{-\left|\mathrm{PPV}_{0}-\mathrm{AV}_{0}\right|}
$$

\section{Results and Discussion}

To illustrate practical application and give recommendations for assessing a company effectiveness of adaptation to the digital economy we will use the

\begin{tabular}{|c|c|}
\hline Tasks & Course of actions \\
\hline \multicolumn{2}{|c|}{ 1. To prepare source data } \\
\hline \multicolumn{2}{|c|}{ Threats - Consumers } \\
\hline \multirow{2}{*}{$\begin{array}{l}\text { Debt service } \\
\text { coverage ratio } \\
\quad(\mathrm{DSCR})\end{array}$} & $\begin{array}{c}\mathrm{AV}_{0} \text { and } \mathrm{AV}_{1}=\text { Net operating income } \\
\text { / Total debt service } \\
\text { are calculated at the beginning and at } \\
\text { the end of the year/ quarter }\end{array}$ \\
\hline & $\begin{array}{c}P P V_{0} \text { and } P P V_{1} \text { are set by experts at } \\
\text { the best value level for several (3-5) } \\
\text { years }\end{array}$ \\
\hline \multirow{2}{*}{$\begin{array}{l}\text { Capacity utilization } \\
\text { rate }\end{array}$} & $\begin{array}{c}\mathrm{AV}_{0} \text { and } \mathrm{AV} \mathrm{V}_{1}-\text { Production volume in } \\
\text { natural units / Production capacity } \\
\text { during the reporting/ study period }\end{array}$ \\
\hline & $\begin{array}{l}\mathrm{PPV}_{0} \text { and } \mathrm{PPV}_{1} \text { characterize full } \\
\text { production capacity utilization and } \\
\text { are equal to } 100 \%\end{array}$ \\
\hline \multirow{2}{*}{$\begin{array}{l}\text { Share of finished } \\
\text { goods inventory in } \\
\text { material costs }\end{array}$} & $\begin{array}{l}\qquad \mathrm{AV}_{0} \text { and } \mathrm{AV}_{1}=\text { Finished goods } \\
\quad \text { inventory / Material costs } \\
\text { are calculated at the beginning and at } \\
\text { the end of the reporting/ study period }\end{array}$ \\
\hline & $\begin{array}{l}P^{P} V_{0} \text { and } P P V_{1} \text { are set by experts at } \\
\text { the best value level for several years }\end{array}$ \\
\hline \multicolumn{2}{|r|}{ Threats - Suppliers } \\
\hline \multirow{2}{*}{$\begin{array}{l}\text { Cost-effectiveness } \\
\text { of raw materials } \\
\text { and energy }\end{array}$} & $\begin{array}{l}\mathrm{AV}_{0} \text { and } \mathrm{AV} V_{1}=\text { Gross profit } / \text { Costs of } \\
\text { raw materials, materials, and energy }\end{array}$ \\
\hline & $\begin{array}{c}P^{P P V_{0}} \text { and } P P V_{1} \text { are set by experts at } \\
\text { the best value level }\end{array}$ \\
\hline \multirow{2}{*}{$\begin{array}{l}\text { Share of raw } \\
\text { materials and } \\
\text { energy reserves in } \\
\text { material costs }\end{array}$} & $\begin{array}{l}\mathrm{AV}_{0} \text { and } \mathrm{AV_{1 }}=\mathrm{Raw} \text { stocks and } \\
\text { energy reserves / Material costs }\end{array}$ \\
\hline & $\begin{array}{l}\mathrm{PPV}_{0} \text { and } P P V_{1} \text { are set by experts at } \\
\text { the best value level for several years }\end{array}$ \\
\hline \multicolumn{2}{|c|}{$\begin{array}{c}\text { Threats - Competition } \\
\end{array}$} \\
\hline \multirow[b]{2}{*}{$\begin{array}{l}\text { Company's market } \\
\text { share }\end{array}$} & $\begin{array}{c}\mathrm{AV}_{0} \text { and } \mathrm{AV}_{1}=\text { Company's output/ } \\
\text { Industrial output }\end{array}$ \\
\hline & $\begin{array}{c}\mathrm{PPV}_{0} \text { and } \mathrm{PPV}_{1} \text { are set by experts at } \\
\text { the best value level for several years } \\
\text { or at the level of the nearest } \\
\text { competitor }\end{array}$ \\
\hline \multicolumn{2}{|c|}{$\begin{array}{l}\text { 2. To input source data } \\
\end{array}$} \\
\hline \multicolumn{2}{|c|}{$\begin{array}{l}\text { 3. To apply a quantitative algorithm for measuring } \\
\text { resultativeness of a company's adaptation to market changes } \\
\text { in the digital economy }\end{array}$} \\
\hline \multicolumn{2}{|c|}{$\begin{array}{l}\text { 4. To calculate constituents of adaptation resultativeness to } \\
\text { market changes in the digital economy for a construction } \\
\text { enterprise }\end{array}$} \\
\hline \multicolumn{2}{|c|}{ 5. To determine and structure costs of adaptation } \\
\hline \multicolumn{2}{|c|}{ 6. To build up a database over several years (quarters) } \\
\hline \multicolumn{2}{|c|}{ 7. To apply a dependency analysis algorithm } \\
\hline \multirow{2}{*}{\multicolumn{2}{|c|}{$\begin{array}{l}\text { 8. To apply an algorithm for calculating an optimal / best } \\
\text { value for adaptation resultativeness }\end{array}$}} \\
\hline & To draw up a report \\
\hline
\end{tabular}
example of a construction enterprise (Table 1).
Table 1. Instructions on evaluating and optimizing a company's adaptation performance.

The course of action for evaluating and optimizing a company adaptation performance:

1. To prepare source data for calculating parameters/ indicators of a company adaptation result, with consumer, suppliers and competitors being considered.

2. To input source data. It is recommended to use Microsoft Excel for computing results.

3. To apply a quantitative algorithm for measuring resultativeness of a company adaptation to market changes in the digital economy. It is recommended that software and a parametric method be used. 
4. To calculate constituents of adaptation resultativeness to market changes in the digital economy for a construction enterprise such as resultativeness of resourcing, resultativeness of executive performance, and resultativeness of forecasting the values of the indicators, which were used as benchmarks for a company adaptation performance. Software and regressive and correlation analysis methods are used.

5. To determine and structure the costs of a construction enterprise adaptation to market conditions.

6. To build up a database over several years (quarters) to optimize the costs and effectiveness of a construction enterprise adaptation to market changes in the digital economy (input of the above source data over several years (quarters), but no less than 16 positions to ensure the reliability of the data further regressive and correlation analysis).

7. To apply a dependency analysis algorithm to analyze correlation between the costs a construction enterprise has incurred while adapting to the market changes in the digital economy and its resultative adaptation performance/ resultativeness. It is recommended that software and regressive and correlation analysis methods are used.

8. To apply an algorithm for calculating an optimal/ best value for resultativeness of adaptation to market changes considering impacts of digital economy and costs of adaptation. It is recommended that software and the Nelder-Mead optimization method are used.

9. To draw up a report on the research results and on the company performance in adapting to market changes in the digital economy.

Assessment of the resultativeness of adaptation in the digital economy should be carried out by qualified personnel with high analytical abilities and the ability to predict, who know the characteristics of the external environment, are able to recognize its signals about the possible impact of changes on the company's activities.

In our opinion, adaptation and, in particular, assessment of the resultativeness of adaptation is possible on the basis of the Department of economic security, which usually operates on large enterprises industrial enterprise. At the same time, the main task would be to analyze the company's activities, analyze the threats that market entities produce, compare the state of the company's activities and the state of market entities, make analytical conclusions about the possible impact of specific market entities, suggest alternative adaptation actions, evaluate the resultativeness of adaptation and suggest corrective actions based on the assessment.

\section{Conclusions}

The digital economy encourages businesses to transform almost all business tools and functions. For successful development in the new environment, enterprises must constantly improve their competence in the field of working with information, and especially in the field of digital technologies for data collection, processing and storage.
Seriously challenged by the need to adapt and adjust to market changes in the digital economy, industrial enterprises have realized the necessity to build up their own organizational and economic system of adaptation to implement the process.

In this connection, sound adaptation management decisions should be based on the results of a company performance monitoring, and, therefore, should consider revealed trends characterizing changes in its performance indicators.

If applied, the proposed in the paper methodology may provide an opportunity to obtain broad data on adaptation effectiveness of business enterprises to market changes in the digital economy.

As all markets today are being shaped and modified under the impact of digital technologies, the main drivers of a company's adjustments are connected with heavily digitalized activities of the key market players suppliers, competitors and consumers.

Databases developed due to monitoring of businesses adaptation performance will help management to strengthen control over the economic security of their enterprises in digital environment, as the reasons for changes can be revealed and analyzed. Thus, having gained an opportunity to make a reasonable redistribution of funds for adaptation measures, these companies will be able to optimize their resources, and improve resultativeness of adaptation to the digital economy.

\section{References}

1. Government of the Russian Federation (2017). The program "Digital Economy of the Russian Federation", approved by the Order of the Government of the Russian Federation of July 28, 2017 No. 1632-p.

2. L.M. Fonseca, Industry 4.0 and the digital society: concepts, dimensions and envisioned benefits // Proceedings of the international conference on business excellence, 12 (1), 386-397 (2018).

3. J. Schlick, P. Stephan, D. Zuhkle, Produktion 2020. Auf dem Weg zur 4.0. industriellen Revolution. IM, (Fachzeitschrift fur Information Management und Consulting, 2012).

4. E. Bucherer, U. Eisert, G. Gassmann, Towards systematic business model innovation: Lessons from product innovation management, Creativity and Innovation Management, 21(2), 183-198 (2018).

5. J.A. Saucedo-Martinez, M. Perez-Lara, J.A. Marmolejo-Saucedo, T.E. Salais-Fierro, P. Vasant, Industry 4.0 framework for management and operations: a review, Journal of ambient intelligence and humanized computing, 9 (3), 789- 801 (2018).

6. M.A. Sneps-Sneppe, V.A. Sukhomlin, D.E. Namiot, On information models of the digital economy // Selected Papers of the II International Scientific Conference "Convergent Cognitive Information Technologies" (Convergent 2017) Moscow, Russia, November 24-26, 367-379 (2017). 
7. R. Ackoff, Journal of Applied Systems Analysis, 16 (1989)

8. P. Drucker, The Practice of Management (Harper \& Brothers, New York, 1954)

9. R. R.Nelson, I.S.J. Winter, Evolutionary Theory of Economic Change. Per. from English M., Delo, 536 (2002)

10. G.V. Dvas, Formation of regional programs of digital economy development. Upravlenie ekonomicheskimi sistemami: elektronnyi nauchnyi zhurnal, 12, 106 (2017).

11. J. Schumpeter, The Theory of Economic Development (Direct media Publishing, Moscow, 2008)

12. V.I. Ananyin, K.V. Zimin, M.I. Lugachev, R.D. Gimranov, \& K.G. Skripkin, Digital enterprise: Transformation into a new reality. Business Informatics, 2(44), 45-54.

13. S.D. Bodrunov, Economic recovery of Russia, 1 (2017)

14. L. Garifova, The economy of the digital epoch in Russia: Development tendencies and place in business. Procedia Economics and Finance, 15, 1159-1164. DOI: 10.1016/S2212-5671(14)00572-3 (2014).

15. G. Rudenko, Digital technologies: New business opportunities. Effective Crisis Management, 1(82), 42-47.

16. L. Gaspareniene, R. Remeikiene, V. Navickas, Procedia Economics and Finance, 39 (2016)

17. V.I. Loyko, E.V. Lutsenko, A.I. Orlov, Modern digital economy, 508 (Krasnodar: KubSAU, 2018)

18. I.P. Boyko, M.A. Yevnevich, A.V. Kolyshkin, Enterprise Economics in the Digital Era, Russian Entrepreneurship, 18(7), 1127-1136 (2017).

19. The development of the digital economy in Russia. Program until 2035.

20. T. V. Avdeenko, A. A. Aletdinova, NauchnoTekhnicheskie Vedomosti SPbGPU

Ekonomicheskie Nauki, 10, 1 (2017).

21. J. Schlick, P. Stephan, D. Zühlke, Produktion 2020: Auf dem Weg zur 4. industriellen Revolution. IM Fachzeitschrift für Information Management und Consulting, 27, 26-33 (2012).

22. E.B. Babayan, R.R. Timergaleeva, I. Yu. Grishin, Distributed infrastructure of the industrial region digital economy ecosystem. International Journal of Open Information Technologies, 7(7) (2019). 